\title{
The effect of deposition power on the electrical properties of Al-doped zinc oxide thin films
}

\author{
B. S. Chun, ${ }^{1}$ H. C. Wu, ${ }^{2}$ M. Abid, ${ }^{3,4}$ I. C. Chu, ${ }^{5}$ S. Serrano-Guisan, ${ }^{6}$ I. V. Shvets, ${ }^{2}$ and \\ Daniel. S. Choi ${ }^{1, a)}$ \\ ${ }^{1}$ Department of Chemical and Materials Engineering, University of Idaho, Moscow, \\ Idaho 83844-3024, USA \\ ${ }^{2}$ CRANN, School of Physics, Trinity College Dublin, Dublin 2, Ireland \\ ${ }^{3}$ IPMC, Ecole Polytechnique Federale de Lausanne, Station 3, CH-1015 Lausanne, Switzerland \\ ${ }^{4}$ King Abdullah Institute for Nanotechnology, King Saud University, Riyadh 11451, Saudi Arabia \\ ${ }^{5}$ Data and Storage R\&D Laboratory, Seocho R\&D Campus, LG Electronics, Seoul 137-130, Republic of \\ Korea \\ ${ }^{6}$ Physikalisch-Technische Bundesanstalt, Bundesallee 100, 38116 Braunschweig, Germany
}

(Received 17 June 2010; accepted 5 August 2010; published online 27 August 2010)

\begin{abstract}
We investigated the effect on the electronic properties of aluminum (Al)-zinc oxide ( $\mathrm{ZnO})$ films by modulating the radio frequency sputtering power. Our experimental results show that increasing the sputtering power increases the Al doping concentration, decreases the resistivity, and also shifts the $\mathrm{Zn} 2 p$ and $\mathrm{O} 1 s$ to higher binding energy states. Our local-density approximation (LDA) and LDA $+U$ calculations show that the shift in higher binding energy and resistivity decrease are due to an enhancement of the $\mathrm{O} 2 p-\mathrm{Zn} 3 d$ coupling and the modification of the $\mathrm{Zn} 4 s-\mathrm{O} 2 p$ interaction in $\mathrm{ZnO}$ induced by $\mathrm{Al}$ doping. (C) 2010 American Institute of Physics.

[doi:10.1063/1.3483232]
\end{abstract}

The zinc oxide $(\mathrm{ZnO})$ film has received considerable attention recently due to its potential application as a transparent and conductive coating material. ${ }^{1,2} \mathrm{ZnO}$ is an n-type wide band gap ( $3.3 \mathrm{eV}$ at room temperature) semiconductor, and its electrical conductivity dominated by $\mathrm{Zn}$ interstitial atoms and oxygen vacancies. The large exciton binding energy (BE) $(60 \mathrm{meV})$ and band gap energy of $\mathrm{ZnO}$ can be tuned by doping with appropriate elements to enhance its optical and electrical performance. To get a low resistivity as well as a high transmittance in the visible region, the $\mathrm{ZnO}$ is usually doped with group III elements such as aluminum (Al), indium (In), gallium (Ga), and boron (B) ${ }^{3-5}$ Doped $\mathrm{ZnO}$ has similar electrical and optical properties to indium tin oxide but it is also much cheaper, more temperature stable, and moreover it is nontoxic.

In the group III element, $\mathrm{Al}$ is considered as the most promising dopant. The highest conductivity values have been found in films with an $\mathrm{Al}$ concentration of $2-3$ at. $\%{ }^{6,7}$ When the $\mathrm{ZnO}$ is heavily doped with $\mathrm{Al}$, however, the resistivity increases because of the depletion in carrier concentration due to reduction in the number of oxygen vacancies in $\mathrm{Al}-\mathrm{ZnO}$ and the neutral impurity scattering due to formation of a sodium $(\mathrm{Na})$ zeolite structure. ${ }^{5,7}$

Many techniques have been employed to prepare $\mathrm{Al}-\mathrm{ZnO}$ thin films, such as magnetron sputtering, ${ }^{8}$ pulsed laser deposition, ${ }^{9}$ and chemical deposition. ${ }^{10}$ It was found that the properties of $\mathrm{Al}-\mathrm{ZnO}$ films are strongly dependent upon the preparation conditions such as the deposition methods, chamber pressure, and substrate temperature ${ }^{8-10}$ Furthermore, it was suggested by Cong et al. ${ }^{11}$ recently that the Al doping can induce an enhancement of $p-d$ coupling in $\mathrm{ZnO}$. However, no theoretical study has been presented and the origin of the effect of $\mathrm{Al}$ doping on electrical properties is still not clear. ${ }^{12,13}$

\footnotetext{
a) Author to whom correspondence should be addressed. Electronic mail: dchoi@uidaho.edu.
}

Here, in this letter, we systematically investigated the effect of radio frequency (rf) sputtering power on the electrical properties of Al-doped $\mathrm{ZnO}$ films. Our experiments show that by increasing the sputtering power, the $\mathrm{Al}$ doping concentration is increased, which decreases the resistivity and also moves the $\mathrm{Zn} 2 p$ and $\mathrm{O} 1 s$ to high BEs energy states. Our local-density approximation (LDA) and LDA+U calculations clearly show that the $\mathrm{Al}$ doping enhances the $p-d$ coupling and also modifies $s-p$ interaction in $\mathrm{Al}$ doped $\mathrm{ZnO}$ which shifts the BE and increases the conductivity, respectively.

The $\mathrm{Al}-\mathrm{ZnO}$ thin film samples were prepared on $(1 \mathrm{in}$. $\times 1$ in.) glass substrates at room temperature using a $\mathrm{rf}$ magnetron sputtering system with a base pressure at about $3 \times 10^{-7}$ Torr. An Al (2 at. \%)-ZnO (98 at. \%) alloy target (purity 99.95\%, 2 in. in diameter, Super Conductor Materials Inc.) was used for the deposition. The sputtering was conducted in Ar atmosphere with a target-to-substrate distance of $7 \mathrm{~cm}$. The working pressure was $2 \times 10^{-3}$ Torr and the applied sputtering power was in the range of $60-180 \mathrm{~W}$.

A Quantum Design Physical Property Measurement System (PPMS) was used to measure the electrical properties of the $\mathrm{Al}-\mathrm{ZnO}$ film. The $\mathrm{x}$-ray diffraction (XRD) of the films was carried out in a Rigaku x-ray diffractometer using a $\mathrm{Cu} K \alpha$ radiation. The chemical state in the films was investigated by $\mathrm{x}$-ray photoelectron spectrometer (XPS) using an Omicron Nanotechnology Spectroscopy system equipped with a monochromated Al $K \alpha \mathrm{x}$-ray source providing a high intensity $1486.7 \mathrm{eV}$ line.

XRD patterns of the $200 \mathrm{~nm}$ thick $\mathrm{Al}-\mathrm{ZnO}$ films are shown in Fig. 1(a) for films grown on glass substrate at different sputtering powers. The $\mathrm{Al}-\mathrm{ZnO}$ films deposited under different power conditions showed strong $\mathrm{ZnO}$ (002) diffraction peaks. To examine the quality of the Al-doped $\mathrm{ZnO}$ films, the $\mathrm{ZnO}(002)$ diffraction peaks were investigated. The positions of $\mathrm{ZnO}$ (002) diffraction peaks were $34.3^{\circ}, 34.2^{\circ}$, and $34^{\circ}$ for films grown at $60 \mathrm{~W}, 120 \mathrm{~W}$, and $180 \mathrm{~W}$, respec- 

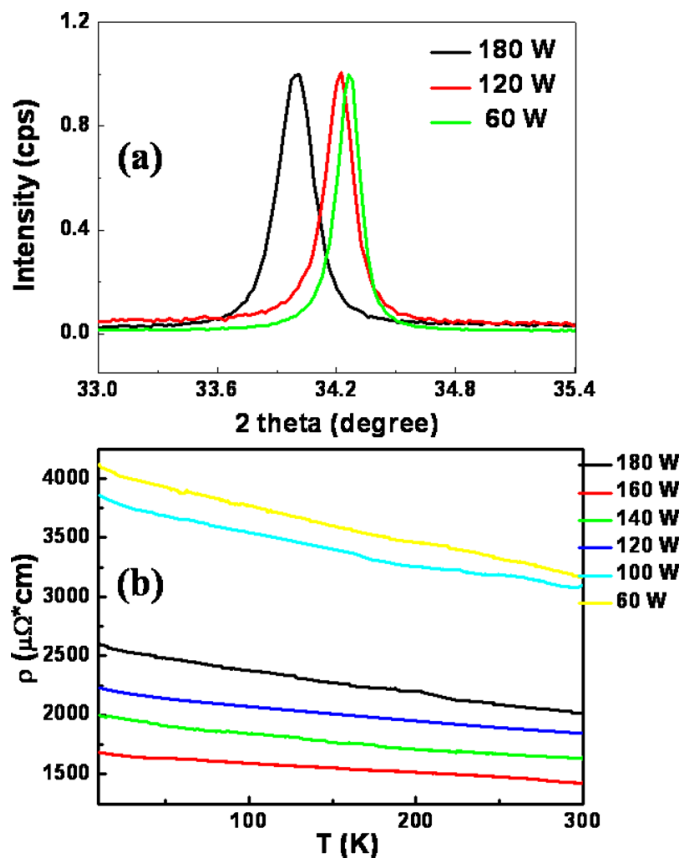

FIG. 1. (Color online) (a) XRD spectra and (b) electrical resistivity of $\mathrm{Al}-\mathrm{ZnO}$ films as a function of sputtering power. A shift in diffraction peaks toward lower angles indicates a higher Al doping concentration with sputtering power results in lower resistivity up to $160 \mathrm{~W}$ of sputtering power.

tively. The presence of a strong (002) diffraction peak indicates a strong $c$-axis orientation to surface of the substrates since the (002) plane is the most closely-packed plane of the $\mathrm{ZnO}$. The (002) diffraction peak obtained in all XRD patterns is very close to that of the pure $\mathrm{ZnO}$ film $\left(34.45^{\circ}\right)$. There is a small difference in the diffraction angles from the standard angle (diffraction peak of pure $\mathrm{ZnO}$ film; $34.45^{\circ}$ ) which appears to be due to the addition of $\mathrm{Al}$ to $\mathrm{ZnO}$ and the $\mathrm{ZnO}$ (002) diffraction peaks shift toward lower angles indicates a higher $\mathrm{Al}$ doping concentration with sputtering power. ${ }^{14}$

Figure 1(b) shows the temperature dependent resistivity curves for the films with different sputtering powers. In the $\mathrm{Al}-\mathrm{ZnO}$ films, the electrical conductivity depends on the contribution from $\mathrm{Zn}, \mathrm{Al}$ interstitial atoms, and oxygen vacancies. Up to $160 \mathrm{~W}$ of sputtering power, the overall resistivity observed in $\mathrm{Al}-\mathrm{ZnO}$ films is that the resistivity decreases when the films are grown at higher sputtering power. All the films show nonmetallic dependence of resistivity versus temperature. Above $160 \mathrm{~W}$ of sputtering power, however, the resistivity increases with increasing power.

The chemical states of the films were investigated by XPS. Figures 2(a) and 2(b) show the O $1 s$ and $\mathrm{Zn} 2 p$ regions, respectively, obtained for the $\mathrm{Al}-\mathrm{ZnO}$ samples grown at different sputtering powers. All regions of each sample have been consistently energy shifted in order to position the peak in the $\mathrm{C} 1 s$ region at a $\mathrm{BE}$ of $284.7 \mathrm{eV}$. These shifts are less than $0.3 \mathrm{eV}$. One can clearly see from Figs. 2(a) and 2(b) that both $\mathrm{O} 1 s$ and $\mathrm{Zn} 2 p$ shift to higher BEs with increased the sputtering power during growth. For the films at $60 \mathrm{~W}$, $120 \mathrm{~W}$, and $180 \mathrm{~W}$, the BE for $\mathrm{O} 1 s$ are $530.6 \mathrm{eV}, 530.7 \mathrm{eV}$, and $530.9 \mathrm{eV}$, respectively. Our XPS measurements further show that the $\mathrm{Al}$ doping concentration increased by increasing the sputtering power during growth. ${ }^{11}$

In order to understand the effect of $\mathrm{Al}$ doping on the electronic structure of $\mathrm{ZnO}$, we present in Figs. 3 and 4 the

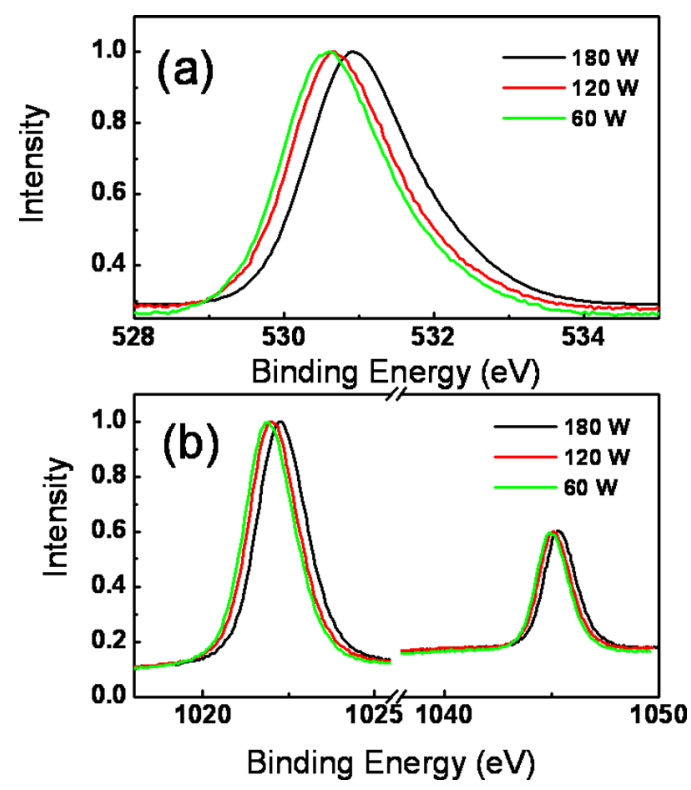

FIG. 2. (Color online) (a) O $1 s$ and (b) $\mathrm{Zn} 2 p$ peaks in the XPS spectrum of the Al-ZnO films as a function of sputtering power. Both $\mathrm{O} 1 \mathrm{~s}$ and $\mathrm{Zn} 2 p$ shift to higher BEs with increased the sputtering power during growth.

calculated electronic structures for an undoped $\mathrm{ZnO}$ and for a $3 \% \mathrm{Al}$ doped $\mathrm{ZnO}$, respectively. The $\mathrm{ZnO}$ has a wurtzite crystal structure with four atoms in the primitive cell. In our calculations, we consider $64(2 \times 4 \times 2)$ atoms. The electronic structure calculation was performed using the Vienna ab initio simulation package. ${ }^{15}$ We employed the projected augmented plane wave ${ }^{16,19}$ and the valence configures of $3 d^{10} 4 s^{2}$ for $\mathrm{Zn}, 2 s^{2} 2 p^{4}$ for $\mathrm{O}$, and $3 s^{2} 3 p^{1}$ for $\mathrm{Al}$ were used.

Figures 3(a) and 3(b) show the partial density of states (DOS) for undoped $\mathrm{ZnO}$ from the LDA and LDA+U calculations, respectively. For the $\mathrm{LDA}+\mathrm{U}$ simulations in this work, we use $\mathrm{U}=6.0 \mathrm{eV}$ and $\mathrm{J}=0 \mathrm{eV} .^{18}$ One can see from Fig. 3 that the band gap is defined by the $\mathrm{O} 2 p-\mathrm{Zn} 4 s$ in-

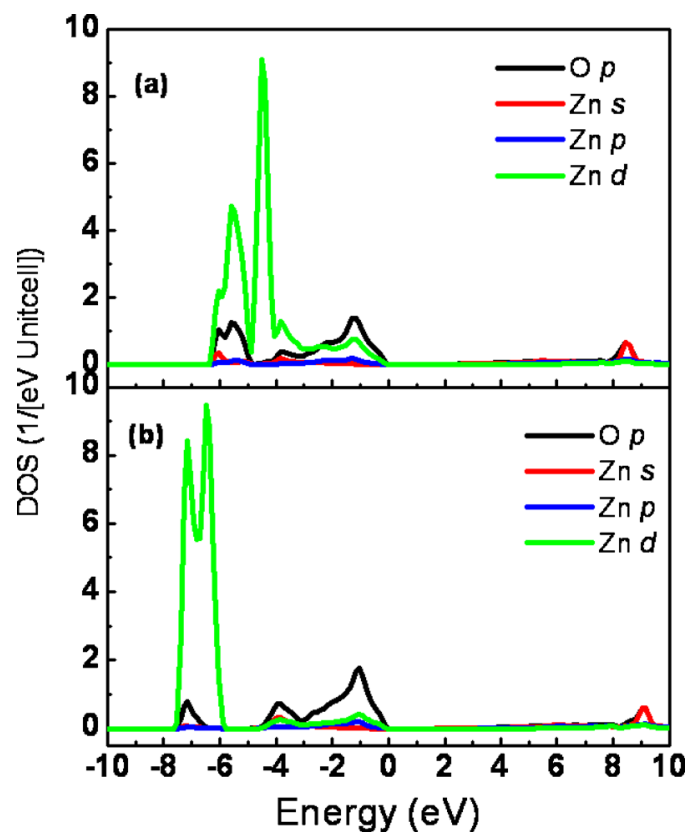

FIG. 3. (Color online) Partial DOS for undoped $\mathrm{ZnO}$ (a) LDA and (b) $\mathrm{LDA}+\mathrm{U}$ calculations where the $\mathrm{O} 2 p, \mathrm{Zn} 4 p, 4 s$, and $3 d$ bands are shown. 

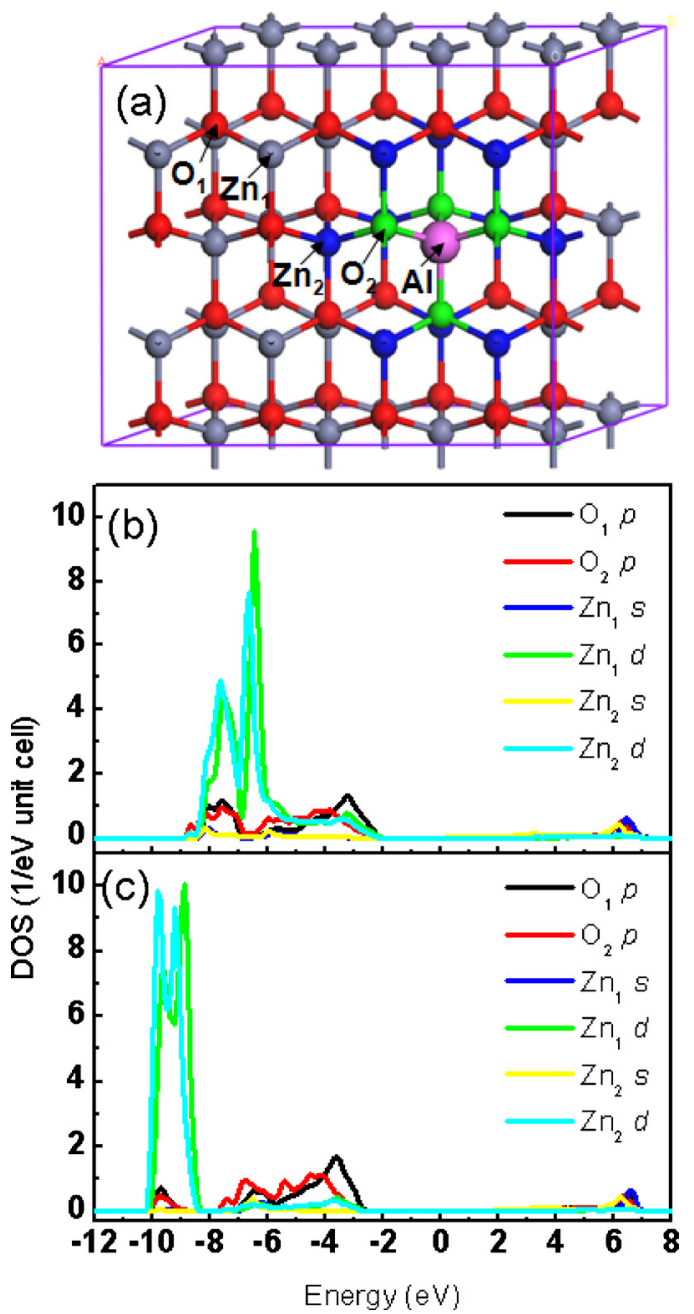

FIG. 4. (Color online) Partial DOS for Al 3\% doped-ZnO (b) LDA and (c) $\mathrm{LDA}+\mathrm{U}$ calculations, (a) where a $\mathrm{Zn}$ atom is substituted by $\mathrm{Al}$ atom.

teraction. A band gap of $0.8 \mathrm{eV}$ is observed, which is consistent with other theoretical reports. ${ }^{13,18}$ The LDA $+\mathrm{U}$ calculation shows a clear energy gap between -5 and $-6 \mathrm{eV}$ in the valence band. Both $\mathrm{O} 2 p$ and $\mathrm{Zn} 3 d$ wave functions are strongly localized and the $\mathrm{O} 2 p$ states are very energetically close to the $\mathrm{Zn} 3 d$ state, which implies a strong $p-d$ hybridization.

Figures 4(b) and 4(c) show the partial DOS after geometry optimization for $\mathrm{Al}$ doped $\mathrm{ZnO}$, where a $\mathrm{Zn}$ atom is substituted by an $\mathrm{Al}$ atom [marked as pink ball in Fig. 4(a)]. Due to strong $s-p$ hybridizations between $\mathrm{Al}$ and $\mathrm{O}$ atoms, four inequivalent oxygen atoms (marked as green balls) come into existence. The bond length for $\mathrm{Al}-\mathrm{O}$ is $1.82 \AA$ which is much smaller than that of $\mathrm{Zn}-\mathrm{O}$ of $1.97 \AA$, which increases the $\mathrm{Zn}-\mathrm{O}$ bonds length formed between 9 s-nextto-Al-neighbor $\mathrm{Zn}$ atoms (marked as blue balls) and four inequivalent oxygen atoms from 1.97 to $2.06 \AA$. One can clearly see from Figs. 4(b) and 4(c) that the DOS for the equivalent $\mathrm{Zn}$ and $\mathrm{O}$ atoms are similar to the undoped $\mathrm{ZnO}$. But for the inequivalent $\mathrm{Zn}$ and $\mathrm{O}$ atoms, the density of the $p-s-d$ states is increased and $\mathrm{O} 2 p$ states are shifted even closer to the $\mathrm{Zn} 3 d$ levels.

Therefore, enhanced $p-d$ hybridization is obviously observed from our calculations. The enhanced $p-d$ coupling lowers the total energy and thus shifts the $\mathrm{Zn} 2 p$ and $\mathrm{O} 1 s$ to higher BE which is consistent with the XPS measure- ments. Moreover, one can see from Figs. 4(b) and 4(c) that the $\mathrm{Zn} 4 s$ states of the inequivalent $\mathrm{Zn}$ atoms also shift to lower energy states of $250 \mathrm{meV}$. It was shown that for a $3 \%$ $\mathrm{Al}$-doped $\mathrm{ZnO}$ film, the band gap is reduced by around 150 $\mathrm{meV}$ with respect to $1 \%$ doped film, ${ }^{12}$ which is in the same energy range as the shift in $\mathrm{Zn} 4 s$ states. Therefore, the shift in $\mathrm{Zn} 4 s$ decreases the energy band gap and also increases the electrical current, which can explain decrease in the resistivity with increasing sputtering power up to $160 \mathrm{~W}$.

For sputter powers above $160 \mathrm{~W}$, the resistivity increases with increasing sputtering power. A possible reason is that the high doping level may lead to a decrease in the mobility of the $\mathrm{Al}-\mathrm{ZnO}$ films and the depletion in carrier concentration due to reduction in the number of oxygen vacancies in $\mathrm{Al}-\mathrm{ZnO}{ }^{6,19}$

In summary, we experimentally and theoretically investigate the effect of the rf sputtering power on the electrical properties of $\mathrm{Al}-\mathrm{ZnO}$ films. Our experiments results show that by increasing the sputtering power, the $\mathrm{Al}$ doping concentration is increased which decreases the resistivity and shift the BE between $\mathrm{Zn} 2 p$ and $\mathrm{O} 1 s$ to high energy states. Our LDA and LDA+U calculations clearly show the enhancement of $\mathrm{O} 2 p-\mathrm{Zn} 3 d$ coupling in $\mathrm{Al}-\mathrm{ZnO}$ and the $\mathrm{Zn} 4 s-\mathrm{O} 2 p$ interaction is responsible for the electrical properties.

This work was supported by the Air Force Office for Scientific Research (Award No. FA9550-08-1-0134) and the University of Idaho New Faculty Start-up Fund. H.C.W. and I.V.S. acknowledge the financial support from Science Foundation of Ireland (SFI) under Contract No. 06/IN.1/I91.

${ }^{1}$ J. F. Wager, Science 300, 1245 (2003).

${ }^{2}$ X. Jiang, F. L. Wong, M. K. Fung, and S. T. Lee, Appl. Phys. Lett. 83, 1875 (2003)

${ }^{3}$ V. Bhosle, A. Tiwari, and J. Narayan, Appl. Phys. Lett. 88, 032106 (2006).

${ }^{4}$ P. Nunes, E. Fortunato, P. Tonello, F. Braz Fernandes, P. Vilarinho, and R. Martins, Vacuum 64, 281 (2002).

${ }^{5}$ O. Bamiduro, H. Mustafa, R. Mundle, R. B. Konda, and A. K. Pradhan, Appl. Phys. Lett. 90, 252108 (2007).

${ }^{6}$ J. Ma, F. Ji, H. L. Ma, and S. Y. Li, Thin Solid Films 279, 213 (1996).

${ }^{7}$ S. S. Lin, J. L. Huang, and P. Sajgalik, Surf. Coat. Technol. 190, 39 (2005).

${ }^{8}$ W. Yang, Z. Liu, D. L. Peng, F. Zhang, H. Huang, Y. Xie, and Z. Wu, Appl. Surf. Sci. 255, 5669 (2009).

${ }^{9}$ J. N. Zeng, J. K. Low, Z. M. Ren, T. Liew, and Y. F. Lu, Appl. Surf. Sci. 197-198, 362 (2002).

${ }^{10}$ G. Gordillo and C. Calderon, Sol. Energy Mater. Sol. Cells 69, 251 (2001).

${ }^{11}$ G. W. Cong, W. Q. Peng, H. Y. Wei, X. L. Liu, J. J. Wu, X. X. Han, Q. S. Zhu, Z. G. Wang, Z. Z. Ye, J. G. Lu, L. P. Zhu, H. J. Qian, R. Su, C. H. Hong, J. Zhong, K. Ibrahim, and T. D. Hu, J. Phys.: Condens. Matter 18, 3081 (2006)

${ }^{12}$ M. Gabás, S. Gota, J. R. Ramos-Barrado, M. Sánchez, N. T. Barrett, J. Avila, and M. Sacchi, Appl. Phys. Lett. 86, 042104 (2005).

${ }^{13}$ P. Palacios, K. Sánchez, and P. Wahnón, Thin Solid Films 517, 2448 (2009).

${ }^{14}$ K. Prabakar, C. M. Kim, and C. M. Lee, Cryst. Res. Technol. 40, 1150 (2005).

${ }^{15}$ G. Kresse and J. Hafner, Phys. Rev. B 47, 558 (1993).

${ }^{16}$ M. C. Payne, M. P. Teter, D. C. Allan, T. A. Arias, and J. D. Joannopoulos, Rev. Mod. Phys. 64, 1045 (1992).

${ }^{17}$ Y. Wang and P. Perdew, Phys. Rev. B 43, 8911 (1991).

${ }^{18}$ C. L. Dong, C. Persson, L. Vayssieres, A. Augustsson, T. Schmitt, M Mattesini, R. Ahuja, C. L. Chang, and J.-H. Guo, Phys. Rev. B 70, 195325 (2004).

${ }^{19}$ W. Tang and D. C. Cameron, Thin Solid Films 238, 83 (1994). 